\title{
International Group for Indigenous Health Measurement: Recommendations for best practice for estimation of Indigenous mortality
}

\author{
Clare Coleman ${ }^{\mathrm{a}, *}$, Brenda Elias ${ }^{\mathrm{b}}$, Vanessa Lee ${ }^{\mathrm{c}}$, Janet Smylie ${ }^{\mathrm{d}, \mathrm{e}}$, John Waldon ${ }^{\mathrm{f}, \mathrm{g}}$, \\ Felicia Schanche Hodge ${ }^{\mathrm{h}}$ and Ian Ring ${ }^{\mathrm{i}}$ \\ a Sydney Centre for Aboriginal and Torres Strait Islander Statistics, University of Sydney, Sydney, Australia \\ ${ }^{\mathrm{b}}$ Faculty of Medicine, Community Health Sciences, University of Manitoba, Winnipeg, Canada \\ ${ }^{\mathrm{c}}$ Faculty of Health Sciences, University of Sydney, Sydney, Australia \\ ${ }^{\mathrm{d}}$ Centre for Research on Inner City Health, Li Ka Shing Knowledge Institute, St. Michael's Hospital, Toronto, \\ Canada \\ ${ }^{\mathrm{e}}$ Dalla Lana School of Public Health, University of Toronto, Toronto, Canada \\ ${ }^{\mathrm{f}} 2$ Tama Ltd, Palmerston North, New Zealand \\ ${ }^{\mathrm{g}}$ School of Public Health and Community Medicine, University of New South Wales, Sydney, Australia \\ ${ }^{\mathrm{h}}$ School of Public Health and Nursing, University of California, Los Angeles, USA \\ ${ }^{\mathrm{i}}$ Research and Innovation Division, University of Wollongong, Wollongong, Australia
}

\begin{abstract}
.
AIM: To provide a best practice guide on Indigenous mortality reporting based on recommendations from the International Group for Indigenous Health Measurement.

METHOD: A workshop of the International Group for Indigenous Health Measurement was held in Montreal in 2013 during which best practices in determining Indigenous mortality were discussed. A subsequent discussion paper and draft recommendations were further refined at a meeting in Vancouver in 2014. A working group finalized this best practice guide in follow-up to the two meetings.

OUTCOME: Ten final recommendations are made regarding identification, community engagement and ownership, data linkage, uncertainty in official statistics and a timeline for implementation. In this paper we review and discuss these recommendations drawing on examples of best practice in Australia, Canada, New Zealand and the United States of America and highlighting some shortcomings in the current practices of official statistical agencies.
\end{abstract}

Keywords: Indigenous, mortality, official statistics

\section{Introduction}

This paper provides a best practice guide on Indige-

${ }^{*}$ Corresponding author: Clare Coleman, Sydney Centre for Abonous mortality reporting. It was developed through the International Group for Indigenous Health Measurement (IGIHM), a network of Indigenous and allied persons representing Indigenous communities and organ- 
isations, government statistical agencies, universities, and non-government arenas in Australia, Canada, New Zealand, and the United States of America (United States). This group shares information on effective strategies, improved methods and policy development to strengthen the collection, analysis, dissemination and use of health information for Indigenous populations.

Accurate mortality data is fundamental to assessing and monitoring levels of health and improving health status. The right to be counted is a fundamental human right, and people must not be denied the right or opportunity to self-identify as Indigenous [?]. The accuracy of Indigenous mortality statistics is entirely dependent upon the complete and accurate ascertainment of Indigenous identification and consequently, collection methods used for standardised data sets both within and between countries. How best to optimise the reporting of this indicator and ways of collecting this information for Indigenous populations is a core issue for health reporting. The right to be counted is a fundamental human right and individuals and groups must not be denied the right or opportunity to self-identify as Indigenous.

Indigenous mortality is calculated using death, census or other records, each of which require a reliable and, ideally, consistent Indigenous identifier for the numerator and denominator. The quality of the data is limited to the poorest quality data set used to estimate a statistic. Without best practice identification in all vital event registrations (birth and death), census, and other denominator registrations, the struggle to achieve a more accurate picture of mortality and life expectancy persists $[?, ?]$. Efforts to correct these issues can be found internationally.

As noted by Madden et al. [?], the United Nations and the World Health Organisation advanced a number of recommendations to improve reporting so that "such countries would be able to produce appropriate and reliable data that adhered to certain professional and scientific standards." Further, the United Nations [?] recommends the collection of vital statistics for provision of services, citizenship issues and general governance for every geographic region and population group in each country and reiterated this in 2014 [?]. It explicitly recommends that race and ethnicity be determined in consultation with the parties affected. More specific to Indigenous populations, article 8 of the United Nations Declaration on the Rights of Indigenous Peoples [?] places a responsibility on Member States to provide effective mechanisms for preven- tion of, and redress for any action which has the aim or effect of depriving them of their integrity as distinct peoples or ethnic identities, or of their cultural values. Article 15 highlights that Indigenous peoples have the right to the dignity and diversity of their cultures, traditions, histories and aspirations which shall be appropriately reflected in education and public information.

\section{Indigenous self-identification}

In the four nations considered in this paper, full vital statistics are collected for the population as a whole. In these vital event data, Indigenous populations, however, have not always been identified consistently or accurately [?,?]. Inconsistencies, inaccuracies, or a lack of identification has led to the under estimation for all or some Indigenous populations in terms of infant mortality [?,?], life expectancy, cancer risk [?], and other indices [?].

Reporting vital statistics on any specific population group requires a reliable identifier in birth and death registrations and national census collections. The collection of race/ethnicity identifiers, however, is inconsistently collected worldwide. For instance, some Scandinavian countries have not collected racial/ethnicity information since World War II [?] with some saying that was to avoid the use and misuse of race information for research based on racist ideology. While this exemption may have been laudable at the time to address the potential for discrimination, non-discrimination is a crosscutting principle in International human rights laws, complimented by the principle of equality. Not collecting ethnicity data may enable the discrimination it seeks to avoid and hide such inequalities. In 2014, the UN nevertheless reiterated that the collection of race/ethnicity in vital registration is dependent upon individual national circumstances. That being said, the risk for discrimination, or not having a consistent identifier has to be balanced against the need for countries to meet their obligations to collect and report accurate data to and for Indigenous communities [?].

Freemantle et al. [?] reported the historical development and cultural influence of European colonisation that influenced the state of Indigenous identification in vital statistics, census and health record data in Australia, New Zealand, Canada and the United States that left a legacy of "excess mortality, morbidity, and trauma that parallels the economic devastation and cultural loss of land alienation" [?] that had its roots in discrimination. 
All countries $[?, ?, ?, ?]$ have acknowledged that current data on Indigenous populations is inadequate [?]. Australia, New Zealand and the United States have taken a national approach to address these data issues [?,?,?], while Canada has devolved the problem and consultations to province, state territory, or Indigenous bodies with very uncertain chance of success.

Health inequalities continue to persist for Indigenous populations in all countries under discussion [?, ?]. Guided by the principles of non-discrimination and equality and in the spirit of the United Nations Declaration on the Rights of Indigenous Peoples, a core responsibility of Government should include working in partnership with Indigenous peoples to collect appropriate statistics to measure the extent of the inequity and to take appropriate action to rectify inequalities. Not only is there an imperative to collect the data but there is a responsibility to disseminate and use the data in a meaningful, effective and non-discriminating way for the benefit and dignity of Indigenous communities. Below we have compiled a number of countryspecific examples that illustrate the data and measurement challenges impeding a full understanding of indigenous health and wellbeing.

\section{Life expectancy as a measure of mortality}

Life expectancy is a headline health indicator but is calculated differently in each country [?]: In Australia, life expectancy is calculated after each 5 yearly census. A direct method was introduced in 2006 and refined in 2011, replacing a range of indirect methods including the Bhat and Hill methods [?]. The new direct method calculates a factor for the under-identification in death registrations determined through a linkage study with the census and death registrations immediately after the census. These are then adjusted through the propensity to identify in the Post Enumeration Survey. These are still experimental and no adjustment for age is produced for the states and territories because the sample size is too small. Further, no adjustment is made for the relatively large numbers of Aboriginal and Torres Strait Islander deaths that cannot be linked to the census. Madden et al. [?] have explored some of the limitations of the methodologies, including the use of the census as the "gold standard" for Indigenous identification rather than using an ever Indigneous methodology. They also highlight the fact Indigenous deaths are underestimated and life expectancy is over estimated.

In Canada, several ways to combine data have been used to estimate life expectancy of First Nations (sta- tus and non-status Indians), Métis and Inuit Indigenous peoples [?]. Statistics on adult deaths are reported to Statistics Canada, which then merges them together to create a national mortality database. This database does not include an Indigenous identifier. The national Indian Registry is the only direct data linkage source to estimate mortality, but only includes First Nations persons registered under the Indian Act, thus excluding more than $30 \%$ of the Indigenous population in Canada. This database is also noted for underestimating birth and death registrations [?]. Studies [?] have also historically linked the long form census to the Mortality Database to report on First Nations (status and non-status Indians), Métis and Inuit mortality. Only a subsample of census participants complete the long form that has the Indigenous identity questions which suggests that there may be issues with small numbers and statistical power. Several data sources when combined can produce life expectancy estimates and projections. Life tables for Registered Indians have been estimated and projected by Statistics Canada Demography Division; life tables for Inuit living in the Inuit Nanagat and the four Inuit land claim regions of which it is comprised are estimated by Statistics Canada using Inuit as a geographic proxy, since the large majority of residents in these northern territories are Inuit [?]. Regardless of sources, these reports undercount First Nations, Métis and Inuit people geographically and by source $[?, ?, ?, ?]$.

In New Zealand [?,?] a new method is being used [?] where ethnicity, for the very few deaths where it is not recorded $(0.2 \%)$, is imputed. Mortality rates are modeled at each age by gender for each population group from the death registrations and population estimates from the most recent Census. The Census is completed every five years and the Māori population is calculated after the adjustment for death and no ethnic response counts. The National Health Index (NHI) system allocates unique identification numbers to all New Zealanders with ethnicity included. This allows more complete Māori identification and this assists in the checking of the deceased through the Index, the identification within the NHI is considered to be accurate. This is an example of best practice [?,?].

In the United States it has not been possible to calculate life expectancy for American Indians and Alaska Natives (AI/ANs) as a whole. There is a program of work [?] currently being undertaken by the US National Center for Health Statistics (NCHS) to estimate AI/AN life expectancy. NCHS currently publishes life expectancy estimates for the US 'white', 'black' and 
'all races' populations. Prior to 2003 the AI/AN categories on death certificates was not included and even now not all states have included this category with collection in only 27 of the 52 registration areas $(50$ US states plus New York City and the District of Columbia). In the 2009 NCHS report there is an alert as to the undercount of deaths for AI/AN groups, however, there are no adjustments made to the count.

Although New Zealand offers an example of best practice, and while it has not translated into equitable outcomes for Māori, this practice has seen policies developed to tackle quantified inequalities but prioritisation of ethnicity also contributes to an undercount of other ethnic groups. The three other countries are making some progress but it is mixed. In line with the UN Sustainable Development Goals for 2030, it is time for the government and statistical agencies to work towards complete and accurate identification in vital statistics for the dignity and equality of Indigenous peoples.

The editors for the Centers for Disease Control and Prevention, in commenting on the situation in United States, summed it up well for all four countries: "Race has not been consistently defined or ascertained in public health and related data sets. For many mortality and morbidity rates, denominators are commonly derived from (U.S.) Census data that rely on respondents' selfidentification. In comparison, race coding for numerator data may reflect a wider range of methods, including designation of race by next-of-kin, a coroner, or other person who certifies the death. Similarly, race coding for reportable diseases may represent the independent designation of a health-care provider." [?].

There are three aspects to the following set of recommendations made by IGIHM. The first four recommendations relate to the vital statistic registers and relationships that need to be maintained or established to ensure accurate Indigenous mortality reporting. The next five relate to the mechanisms that can be put in place until the vital statistics collections are adequate for Indigenous mortality reporting. The final recommendation provides a timeline for implementation in light of the United Nations 2030 Sustainable Development Goals.

\section{IGIHM recommendations}

1. There should be Indigenous identifiers on national census, birth and death certificates using the same definitions and nomenclature in each.
The collection of Indigenous identifiers has been slowly initiated during the past 45 years. In Australia, Aboriginal and Torres Strait Islanders were officially counted in the census beginning in 1971. In the 1980s identification was included for birth and death registration in most jurisdictions, although Indigenous identifier in death registrations in Queensland was only introduced in 1997. There is still substantial underregistration in death registration and under enumeration in the Census [?,?,?]. In Canada, there is no universal identification protocol or process for Indigenous identifiers [?]. Such identification in the Census was removed in 2006. In 2015 the new Canadian Government announced the reinstatement of the long form census for the 2016 census which is to be applauded [?]. Vital registrations, however, are mixed with some provinces requiring an identifier on birth registration but not on death registration forms. The collection of identifiers for use in disease surveillance is limited.

In New Zealand there is consistent identification in Census, vital registration and disease surveillance and under identification has been reduced for most hospital admission and mortality data, alongside the use of a national health index number [?].

In the United States a series of studies have uncovered high rates of racial misclassification of $\mathrm{AI} / \mathrm{AN}$ persons $[?, ?, ?, ?, ?, ?, ?, ?, ?, ?, ?, ?, ?, ?]$, resulting in inaccurate mortality and cancer data that are essential for program planning, health service delivery and evaluation $[?, ?, ?, ?, ?, ?, ?, ?, ?, ?, ?, ?, ?, ?]$. Jim et al. [?] reported that racial misclassification of AI/ANs varied by region and was less likely to be reported in error in regions of high concentration of Indigenous populations such as Alaska, California and the Plains states. However, even in these states, researchers have found mismatches in reporting of birth and death certifications as individuals may be identified as AI/AN on their birth certificate and categorised as another race on their death certificate.

2. Self-identification should be the method for establishing Indigenous status in national census and relatives should provide identification for death records; to ensure effectiveness, the mechanisms for monitoring need to be developed, implemented and evaluated with Indigenous people, and the reporting needs to be universal.

In all jurisdictions, self-identification is the method for establishing Indigenous status in the Census [?, ?,?]. In birth and death registration self, or family, identification is recommended although in practice the "eyesight test" is often conducted and funeral direc- 
tors, who generally complete the death registrations, do not always ask the identification question. The previous sections highlight the lack of consistency in death registration information and the need for Canada and the United States to include Indigenous identifiers in birth and death registrations and in national mortality databases.

3. Indigenous communities should be engaged at all stages of data collection, analysis and dissemination of results and principles of Indigenous community ownership and reporting need to be established and maintained for all data collections.

Vital registration records are generally not held and maintained by Indigenous communities; rather they are the responsibility of the state. Ownership models such as formal data use agreements can be used to give communities control over analysis and dissemination of results produced from administrative data sets and ensure meaning and relevance for the Indigenous communities whose data has been collected [?,?]. Creative methods of community dissemination also need to be devised, as well as ways to translate results into meaningful information for Indigenous communities. In Australia, the National Advisory Group on Aboriginal and Torres Strait Islander Health Information and Data (NAGATSIHID), has endorsed 11 principles relating to the collection, use and dissemination of data relating to Aboriginal and Torres Strait Islander peoples [?]. In Canada, First Nations leaders have formally negotiated administrative data agreements (including vital registration data) in British Columbia [?] (with the province) and Ontario [?] (with the Institute of Clinical Evaluative Sciences (ICES)) so that there is First Nations governance over data linkages and analyses. Provincial Indigenous organisations representing Indigenous people living in urban areas in Ontario have also negotiated research and data sharing agreements with ICES. Perhaps the most outstanding example of Indigenous governance and leadership of Indigenous health information in Canada is the First Nations Regional Longitudinal Health Survey which is completely First Nations owned and controlled and represents the largest on-reserve First Nations health dataset in Canada [?].

In New Zealand there are specific Indigenous oversight groups, some officially sanctioned in law [?] and Government supported, for example, and this key group was supported by Te Kete Hauora in the Ministry of Health, and remains an essential task for the Kaitiake Groups for Breast and Bowel Cancer Screen- ing [?] that will require the ongoing and national oversight provided by Te Kete Hauora.

In the United States, there are university and state based organisations working on community engagement $[?, ?]$ but no national centres.

4. Partnerships need to be established between Indigenous peoples and statistical agencies to plan for sustainable national and regional data collection.

NAGATSIHID [?] was established in 2001 and is an example of where an advisory group has been established with a mandated Indigenous majority in a group which includes all relevant statistical organisations. Further, the Australian Bureau of Statistics established an Indigenous roundtable in 2013 to help improve the quality of census and survey data and improve the statistical literacy for Aboriginal and Torres Strait Islander people [?].

In addition to the partnerships described in the previous section between Indigenous governing bodies and/or organisations and the Province of British Columbia and ICES in Ontario, the federal government of Canada (Statistics Canada and Human Resources and Social Development Canada) partnered with Aboriginal organisations and advisors to create the Aboriginal children's survey in 2006 [?]. Unfortunately, this survey has been discontinued.

The goals of the Māori health business unit within the Ministry of Health, New Zealand, Te Kete Hauora, are developing and maintaining relationships with key agencies and organisations such as Statistics New Zealand, and in so doing Māori community and health organisations feel confident that Te Kete Hauora's advice works for Māori and makes a difference for Māori health. As a consequence of its dis-establishment in March 2016, a new champion will be required to ensure the relationships Te Kete Hauora developed remain active and Maori health data is fit for purpose.

The United States has no official partnerships established.

5. Where vital statistical records have incomplete identification or registration, triangulation from a variety of data sources needs to be considered.

In Australia, while there is currently no ongoing routine data linkage approach by statistical agencies, researchers have linked mortality data to hospital admission data [?] and to local Aboriginal Community Controlled Health Organisations [?]. Further, the Australian Institute of Health and Welfare have conducted a feasibility study linking, death registrations, residen- 
tial aged care data, the National hospital morbidity database and the National perinatal database to enhance identification [?] and is developing a system of ongoing linkage of birth death and perinatal records.

If linkages need to be used to determine Indigenous identity in an existing mortality dataset, completeness of Indigenous identification may be improved by increasing the number of datasets being drawn upon for Indigenous identification. For example in New Zealand, there are multiple administrative databases that can be drawn upon to support Māori identification in cancer registries and it has been demonstrated that more inclusive Māori identification (and subsequently more accurate documentation of health inequities) occurs when multiple Māori identity databases are linked [?].

This should not imply an acceptance of inadequate data systems and the main priority should be improving the accuracy and completeness of Indigenous identification in administrative and vital record systems. It should also be noted that linkage of multiple systems, each of which has unknown levels of incomplete identification is not a panacea unless there is some way of determining the completeness of identification of the linked data set. The use of discrete individuals as the basis for the collection and analysis of vital statistics can be in tension with Indigenous conceptualisations and valuing of the inter-relationships between people and their lived environment. Mapping social networks is a tool that supports understanding how relationships between people may impact health and wellbeing [?,?]. Community level aggregation and multi-level modelling that looks at individual and collective health determinants may also assist in refining statistical models that better reflect Indigenous conceptualisations of health.

6. Best practice linkage practices should be established to enhance vital statistics collections and adjust for under identification.

As noted above, data quality is foundational and data linkage should only be a short-term solution for data quality issues - there is an obligation not simply to estimate incomplete under identification but to rectify the underlying data quality problems.

Data linkage may be the most practical short-term corrective method to enhance Indigenous identity in administrative and vital data sets, but to be effective, the linkage ideally requires complete and accurate identification or other sources in at least one of the data sets.
In Australia [?] and New Zealand [?] major linkage projects are undertaken by national bodies to determine under identification in death records to attempt to determine life expectancy more accurately, although there has been some criticism of the methodology used in Australia [?]. Further, in New Zealand there is a central linkage unit which routinely links administrative data [?] with four or five sources of Māori identification that can be cross - referenced. In Canada, linkage projects are undertaken nationally via health reporting initiatives involving the Federal Ministries of Statistics Canada [?,?], Health Canada, and Indigenous and Northern Affairs Canada. Provincially, while data linkage is commonly performed as part of provincial health reporting, data linkage and reporting pertinent to Indigenous populations is not an annual event, is not consistently done across provinces, and the data produced is not standardised for cross-jurisdiction comparative purposes. In some regions, data linkage is driven primarily by academic units or through academic leadership to make health reporting accountable and transparent.

The US Census Bureau has been undertaking census projects to examine changing patterns of identification [?] and, as mentioned above, the NCHS has a data linkage project planned to link census records and mortality data from the 2010 Census [?].

Pitfalls exist where linkages cannot be made and where Indigenous status differs across data sets. Consistency in the numerator and denominator are desirable and methodologies to account for this must be ascertained. Consistency and accuracy may not be totally compatible, so judgment is essential [?,?].

7. Back casting for estimation of health trends needs to be based on sound underpinning assumptions of mortality trends to avoid circularity.

When mortality or disease trends are reported a consistent population is required. Population backcasting is performed to determine what the population would have been in the years prior to the census to arrive at the current population count. This calculation requires mortality estimates to be used. When this in turn is used to describe mortality trends the argument can become circular. Hence the requirement for some external, validated measure for the mortality assumption. In Australia [?], back casting and projections from the 2011 census have been prepared from 1991 to 2026 . It is noted that caution needs to used when using the back casting results for long periods of time as the cumulative effects of assumptions may become compounded 
over time [?]. Similarly in New Zealand, back casting results to 1991 are available [?]. In Canada and the United States there is little official trend reporting of mortality; the issue of unexplained growth in the Indigenous population is discussed in many publications [?,?] but there are no official back cast population estimates.

8. Indirect methods can be used for calculation of life tables but assumptions need to be checked carefully.

The United Nations [?] recommends the use of indirect methods when defective demographic data is all that is available. Multiple techniques are available but their robustness needs to be evaluated. Indirect methods were used in Australia until 2006 but have been discarded because of the many problems associated with them [?,?]. Nonetheless they have their place when the underlying assumptions hold.

9. As mortality estimates are unlikely to ever be $100 \%$ correct, the plausibility of results by age, geography and other parameters should always be considered and uncertainty needs to be specifically acknowledged in official statistics

In Australia, life expectancy and improvements in it, are quoted to one decimal point when the uncertainty around the results, given uncertainty in both numerator and denominator are \pm 1.3 years [?]. Estimates for life expectancy in each country have changed significantly over time as different methods for estimating populations and deaths are used and it is far from clear that the estimates, for some at least of the countries, may not change significantly in the future. Official estimates need to clearly indicate both positive aspects of new methods and resultant estimates and also apparent problems, inconsistencies or uncertainties.

10. To achieve UN inspired Sustainable Development Goals each national and state/territorial government by 2018 should have the required partnership agreements with Indigenous peoples, have launched self-identification processes to produce the Indigenous identifiers required to monitor this progress, and have stated goals to improve Indigenous outcomes.

In 2015, the UN adopted Agenda 21 Sustainable Development Goals and annual reporting. While countries discuss what indicators to develop and report on these goals, those for health such as mortality indicators are standard fare. Disaggregating data to make Indigenous health states transparent, which is consistent with achieving human rights, is mandatory, par- ticularly when there is discrimination. Australia, New Zealand, Canada and the United States have such a track record and by virtue of this history have an obligation to report on Indigenous populations. By 2030, these respective countries should, as in Australia, aim to eliminate gaps between Indigenous and nonIndigenous life expectancy [?] and end inequality in preventable deaths of Indigenous newborns and children under-5 years of age, particularly by closing the gap in neonatal mortality and under-5 mortality.

\section{Conclusion}

Indigenous health in the United States, Canada, Australia and New Zealand, although improving, continues to reflect the adverse effect of colonisation. The right to be counted is a fundamental right and accurate Indigenous mortality and other health data is an essential underpinning requirement for action to sustainably improve Indigenous health and dignity. Provision of the necessary mortality data has been and remains a challenge, although progress is being made. This paper sets out ten best practice recommendations for the provision of mortality data. Action to improve the accuracy and completeness of Indigenous mortality data needs to be based respect for the differences between Indigenous and non-Indigenous ways of doing and knowing in measurement methodology and requires genuine partnerships between Indigenous peoples and statistical agencies. Decisions by statistical agencies have real world consequences in terms of funding and policy and we urge countries with Indigenous populations to develop national plans which incorporate these ten recommendations with the aim of having reliable data by 2030 in line with the UN Sustainability Goals, and to develop and implement annual reporting of progress towards that goal.

\section{Acknowledgement}

We would like to acknowledge the help and advice of Dr Sam Notzon, Director, US National Centre for Health Statistics.

\section{References}

[1] J. Freemantle, I. Ring, T.G.A. Solomon, F.C. Gachupin, J. Smylie, T.L. Cutler et al., Indigenous mortality (revealed): The invisible illuminated, Am J Public Health 105(4) (2015), 644. doi: 10.2105/ajph.2014.301994. 
[2] T. Blakely, M. Soeberg, K. Carter, R. Costilla, J. Atkinson and D. Sarfati, Bias in relative survival methods when using incorrect life-tables: Lung and bladder cancer by smoking status and ethnicity in New Zealand, International Journal of Cancer 131(6) (2012), E974. doi: 10.1002/ijc.27531.

[3] J. Smylie and M. Anderson, Understanding the health of Indigenous Peoples in Canada: Key methodological and conceptual challenges, CMAJ: Canadian Medical Association Journal 175(6) (2006), 602. doi: 10.1503/cmaj.060940.

[4] R. Madden, P. Axelsson, T. Kukutai, K. Griffiths, C.S. Mienna, N. Brown et al., Statistics on Indigenous Peoples: International Effort Needed, Statistical Journal of the IAOS 32(1) (2016), 5. doi: 10.3233/SJI-160975.

[5] United Nations. The Principles and Recommendations for a Vital Statistics System, Revision 2, New York: United Nations, 2001 92-1-161439-2.

[6] United Nations General Assembly, Fundamental Principles of Official Statistics, UN, 2014.

[7] United Nations General Assembly. United Nations Declaration on the Rights of Indigenous Peoples: Adopted by the General Assembly on 13 September 2007, UN, 2008.

[8] Australian Institute of Health and Welfare, Comparing life expectancy of indigenous people in Australia, New Zealand, Canada and the United States: conceptual, methodological and data issues, Canberra: AIHW, 2011.

[9] J. Smylie and M. Firestone, Back to the basics: Identifying and addressing underlying challenges in achieving high quality and relevant health statistics for indigenous populations in Canada, Statistical Journal of the IAOS 31(1) (2015), 67. doi: 10.3233/SJI-150864.

[10] B. Elias, Moving beyond the historical quagmire of measuring infant mortality for the First Nations population in Canada, Social Science \& Medicine 123 (2014), 125. doi: 10.1016/j. socscimed.2014.10.056.

[11] B. Elias, K. Busby and P. Martens, One little too little: counting Canada's indigenous people for improved health reporting, Social Science \& Medicine 138 (2015), 179. doi: 10.1016/j. socscimed.2015.06.014.

[12] S. Hill, D. Sarfati, B. Robson and T. Blakely, Indigenous inequalities in cancer: What role for health care? ANZ journal of surgery, Surgery 83(1-2) (2013), 36. doi: 10.1111/ans. 12041.

[13] P. Axelsson, Abandoning "the other": Statistical enumeration of Swedish Sami 1700 to 1945 and beyond, Berichte Zur Wissenschaftsgeschichte 33(3) (2010), 263. doi: 10.1002/bewi. 201001469.

[14] T.S. Harwell, D. Hansen, K.R. Moore, D. Jeanotte, D. Gohdes and S.D. Helgerson, Accuracy of race coding on American Indian death certificates Montana 1996-1998, Public Health Reports 117(1) (2002), 44.

[15] T. Blakely, J. Atkinson and J. Fawcett, Ethnic counts on mortality and census data (mostly) agree for 2001-2004: New Zealand Census-Mortality Study update, New Zealand Medical Journal 121(1281) (2008), 58.

[16] Statistics New Zealand. Understanding and working with ethnicity data: A technical paper, Wellington: Statistics New Zealand, 2005.

[17] Ministry of Health. Ethnicity data protocols for the health and disability sector, Ministry of Health Wellington, New Zealand, 2004.

[18] Australian Institute of Health and Welfare, Australian Bureau of Statistics, Recent developments in the collection of Aboriginal and Torres Strait Islander health and welfare statistics 2005 Canberra: AIHW \& ABS, 2006.
[19] M. Gracey and M. King, Indigenous health part 1: Determinants and disease patterns, Lancet 374(9683) (2009), 65. doi: 10.1016/S0140-6736(09)60914-4.

[20] M. King, A. Smith and M. Gracey, Indigenous health part 2 : The underlying causes of the health gap, Lancet 374(9683) (2009), 76.

[21] T. Barnes, L. Smith, Y. Zhao and S. Guthridge, A comparative analysis of indirect methodologies for estimating Indigenous life expectancy, Darwin: School for Social and Policy Research, Charles Darwin University, 2008.

[22] R. Madden, L. Tickle, L.J. Pulver and I. Ring, Estimating Indigenous life expectancy: Pitfalls with consequences, Journal of Population Research 29(3) (2012), 269. doi: 10.1007/ s12546-012-9085-6.

[23] Statistics Canada, Projections of Aboriginal populations, Canada, Provinces and Territories, 2001-2007. Ministry of Industry 2007 Ottawa: No. 91-547-XIE.

[24] Statistics Canada, Mortality of Métis and Registered Indian adults in Canada: An 11-year follow-up study, Ottawa: Ministry of Industry 2009 Ottawa: No. 82-003-XPE.

[25] Statistics Canada, Mortality rates among children and teenagers living in Inuit Nunangat, 1994 to 2008, Ottawa: Ministry of Industry, 2012, Ottawa: No. 82-003-XPE.

[26] Statistics Canada, Health Profile, 2013 [cited 201515 Dec]. Available from: http://www12.statcan.gc.ca/health-sante/82228/index.cfm?Lang=E.

[27] Statistics New Zealand, New Zealand Period Life Tables: 2012-14 Wellington: Statistics New Zealand, 2015 [cited 201522 Dec]. Available from: http://www.stats.govt.nz/ browse_for_stats/health/life_expectancy/NZLifeTables_ HOTP12-14/Data\%20Quality.aspx.

[28] Statistics New Zealand, Deaths Wellington: Statistics New Zealand, 2015 [cited 210625 Mar]. Available from: http:// www.stats.govt.nz/browse_for_stats/population/deaths.aspx.

[29] E. Arias, editor Towards the next generation of record linkage studies to advance data quality assessment of civil registrations in low and middle-income coutries, IUSSP-PAA-WBG Meeting on CRVS \& Record Linkage; 2016; Washington DC.

[30] Centers for Disease Control and Prevention, Classification of American Indian race on birth and infant death certificates California and Montana, MMWR Morbidity and Mortality Weekly Report 42(12) (1993), 220.

[31] Australian Bureau of Statistics, Registered Indigenous Deaths 2008 [cited 20158 Sept]. Available from: http://www.abs.gov. au/ausstats/abs@.nsf/0/23E5413F51E806DDCA2576780025 B0C9?opendocument.

[32] Australian Bureau of Statistics, Life Tables for Aboriginal and Torres Strait Islander Australians. Canberra: ABS, 2013 3302.0.55.003.

[33] Office of the Prime Minister, Minister of Innovation, Science and Economic Development Mandate Letter Ottawa, Canada 2015 [cited 201525 Nov]. Available from: http://pm.gc.ca/ eng/minister-innovation-science-and-economicdevelopment-mandate-letter.

[34] Ministry of Health, editor, Tatau Kahukura: Maori Health Chart Book, 3 ed. Wellington: Ministry of Health; 2015.

[35] E. Arias, W.S. Schauman, K. Eschbach, P.D. Sorlie and E. Backlund, The validity of race and Hispanic origin reporting on death certificates in the United States, Vital and Health Statistics Series 2, Data Evaluation and Methods Research (148) (2008), 1.

[36] R.A. Hahn, B.I. Truman and N.D. Barker, Identifying ancestry: The reliability of ancestral identification in the United States by self proxy interviewer and funeral director, Epidemi- 
ology (1996), 75.

[37] R.A. Hahn, S.F. Wetterhall, G.A. Gay, D.S. Harshbarger, C.A Burnett, R.G. Parrish et al., The recording of demographic information on death certificates: A national survey of funeral directors, Public Health Reports 117(1) (2002), 37.

[38] G.N. Ioannou, M.K. Chapko and J.A. Dominitz, Predictors of colorectal cancer screening participation in the United States, The American Journal of Gastroenterology 98(9) (2003), 2082.

[39] S. Kwong, C. Perkins, K. Snipes and W. Wright, Improving American Indian cancer data in the California cancer registry by linkage with the Indian Health Service, J Registry Manage 25(1) (1998), 17.

[40] C.J. Mettlin, H.R. Menck, D.P. Winchester and G.P. Murphy, A comparison of breast colorectal lung and prostate cancers reported to the national cancer data base and the surveillance epidemiology and end results program, Cancer 79(10) (1997), 2052.

[41] A. Noymer, A.M. Penner and A. Saperstein, Cause of death affects racial classification on death certificates, PLoS One 6(1) (2011), e15812.

[42] M.R. Partin, S.J. Rith-Najarian, J.S. Slater, J.E. Korn, N. Cobb and J.T. Soler, Improving cancer incidence estimates for American Indians in Minnesota, American Journal of Public Health 89(11) (1999), 1673.

[43] G.S. Poe, E. Powell-Griner, J.K. McLaughlin, P.J. Placek, G.B. Thompson and K. Robinson, Comparability of the death certificate and the 1986 National Mortality Followback Survey, 1993.

[44] E. Puukka, P. Stehr-Green and T.M. Becker, Measuring the health status gap for American Indians/Alaska Natives: Getting closer to the truth, American Journal of Public Health 95(5) (2005), 838.

[45] H.M. Rosenberg, J.D. Maurer, P.D. Sorlie, N.J. Johnson, M.F. MacDorman, D.L. Hoyert et al., Quality of death rates by race and Hispanic origin: A summary of current research 1999, $\mathrm{Vi}$ tal and Health Statistics Series 2, Data Evaluation and Methods Research (128) (1999), 1.

[46] P. Stehr-Green, J. Bettles and L.D. Robertson, Effect of racial/ethnic misclassification of American Indians and Alaskan Natives on Washington State death certificates 19891997, American Journal of Public Health 92(3) (2002), 443.

[47] J. Swan and B.K. Edwards, Cancer rates among American Indians and Alaska Natives, Cancer 98(6) (2003), 1262.

[48] M.A. Jim, E. Arias, D.S. Seneca, M.J. Hoopes, C.C. Jim, N.J. Johnson et al., Racial misclassification of American Indians and Alaska Natives by Indian Health Service contract health service delivery area, American Journal of Public Health 104(S3) (2014), S295

[49] Australian Institute of Health and Welfare. National best practice guidelines for collecting Indigenous status in health data sets. Canberra: AIHW, 2010.

[50] J. Smylie, M. Firestone, L. Cochran, C. Prince, S. Maracle, M. Morley et al., Our Health Counts 2011 [cited 201615 Mar] Available from: http://www.ourhealthcounts.ca/images/PDF/ OHC-Report-Hamilton-ON.pdf.

[51] M. Firestone, J. Smylie, S. Maracle, M. Spiller and P. O'Campo, Unmasking health determinants and health outcomes for urban First Nations using respondent-driven sampling, BMJ Open 4(e004978) (2014). doi: 10.1136/bmjopen2014-004978.

[52] Australian Institute of Health and Welfare, National Advisory Group on Aboriginal and Torres Strait Islander Health Information and Data (NAGATSIHID) 2015 [cited 201527 Aug].
Available from: http://www.aihw.gov.au/nagatsihid/.

[53] First Nations Health Authority, British Columbia Ministry of Health, Health Canada, Tripartite Data Quality and Sharing Agreement, 2012.

[54] Institute for Clinical Evaluative Sciences, Cheifs of Ontario 2016 [cited 201615 Mar]. Available from: http://www.ices. on.ca/Research/Collaborations-Partnerships/Chiefs $\% 20$ of $\%$ 20Ontario.

[55] The First Nations Information Governance Centre, First Nations Regional Health Survey: The First Nations Information Governance Centre; 2016 [cited 201616 Mar]. Available from: http://fnigc.ca/our-work/regional-health-survey/aboutrhs.html.

[56] Health (Cervical Screening (Kaitiaki)) Regulations 1995 Stat. SR 1995/29 (27 February 1995, 1995).

[57] Ministry of Health, Litmus Limited, The Centre for Public Health Research. Interim Evaluation Report of the Bowel Screening Pilot Screening Round One: Ministry of Health; 2015 [cited 201520 Jun]. Available from: http://www.health. govt.nz/system/files/documents/publications/interimevaluation-report-bowel-screening-pilot-jun15.pdf.

[58] Native American Community Development Institute, 2015 [cited 201616 Mar]. Available from: http://www.nacdi.org/.

[59] Community Engagement Center, Native American Engagement: Pitzer College; 2015 [cited 201616 Mar]. Available from: http://pitweb.pitzer.edu/cec/native-Americanengagement/.

[60] Australian Bureau of Statistics, ABS establishes Round Table on Aboriginal and Torres Strait Islander Statistics Canberra: ABS; 2013 [cited 201527 Aug]. Available from: http://www. abs.gov.au/ausstats/abs@.nsf/products/ACBECE9AD3F3BF D0CA257B6B00236761? OpenDocument.

[61] Statistics Canada, Aboriginal Children's Survey, 2006: Concepts and Methods Guide 2006 [cited 201616 Mar]. Available from: http://www.statcan.gc.ca/pub/89-634-x/89-634x2008006-eng.htm.

[62] L.K. Taylor, J. Bentley, J. Hunt, R. Madden, S. McKeown, P. Brandt et al., Enhanced reporting of deaths among Aboriginal and Torres Strait Islander peoples using linked administrative health datasets, BMC Med Res Methodol 12 (2012), 91. doi: 10.1186/1471-2288-12-91.

[63] B. Phillips, S. Morrell, R. Taylor and J. Daniels, A review of life expectancy and infant mortality estimations for Australian Aboriginal people, BMC Public Health 14 (2014), 1. doi: 10.1186/1471-2458-14-1.

[64] Australian Institute of Health and Welfare, An enhanced mortality database for estimating Indigenous life expectancy: A feasibility study. Canberra, 2012.

[65] Australian Bureau of Statistics, Death Registrations to Census Linkage Project - Methodology and Quality Assessment Australia 2011-2012, Canberra: ABS, 2013.

[66] S. Ajwani, T. Blakely, B. Robson, J. Atkinson and C. Kiro, Unlocking the numerator-denominator bias III: Adjustment ratios by ethnicity for 1981-1999 mortality data, The New Zealand Census-mortality Study New Zealand Medical Journal 116(1175) (2003), U456.

[67] Statistics New Zealand, Linking methodology used by Statistics New Zealand in the Integrated Data Infrastructure project 2014 [cited 201629 Feb]. Available from: http://www.stats. govt.nz/browse_for_stats/snapshots-of-nz/integrated-datainfrastructure/linking-methodology-statsnz-idi. aspx.

[68] Statistics Canada, Avoidable mortality among First Nations adults in Canada: A cohort analysis, Ottawa: Ministry of Industry 2015 Ottawa: No. 82-003-XPE. 
[69] C.A. Liebler, S. Rastogi, L.E. Fernandez, J.M. Noon and S.R. Ennis, America's churning races: race and ethnic response changes between census 2000 and the 2010 census, Washington DC: Center For Administrative Records Research and Applications, 2014.

[70] Australian Bureau of Statistics, Estimates and Projections, Aboriginal and Torres Strait Islander Australians Canberra: ABS, 2014.

[71] C. Coleman, N. Fortune, V. Lee, G. Kalinda and R. Madden, Aboriginal and Torres Strait Islander Life Expectancy and Mortality Trend Reporting: Sydney Centre for Aboriginal and Torres Strait Islander Statistics; 2015 [cited 201616 Mar]. Available from: http://sydney.edu.au/health-sciences/scatsis /docs/AboriginalandTorresStraitIslanderLifeExpectancyand MortalityReporting.pdf.

[72] Statistics New Zealand, Māori Population Estimates: At June 2015 - tables: New Zealand Government; 2015 [cited 2015 15 Dec]. Available from: http://www.stats.govt.nz/browse_ for_stats/population/estimates_and_projections/Maori PopulationEstimates_HOTPAtJun15.aspx.
[73] J.S. Passel, The growing American Indian population 19601990: beyond demography, Population Research and Policy Review 16(1-2) (1997), 11.

[74] Statistics Canada, Population Projections by Aboriginal Identity in Canada, 2006 to 20312015 [cited 201617 Mar]. Available from: http://www.statcan.gc.ca/pub/91-552-x/91-552x2011001-eng.htm.

[75] United Nations, Manual X: indirect techniques for demographic estimation: a collaboration of the Population Division of the Department of International Economic and Social Affairs of the United Nations Secretariat with the Committee on Population and Demography of the National Research Council, United States National Academy of Sciences. New York: United Nations; 1983.

[76] Australian Bureau of Statistics, Discussion Paper: Assessment of Methods for Developing Life Tables for Aboriginal and Torres Strait Islander Australians, 2006.

[77] Council of Australian Governments. National Indigenous Reform Agreement (Closing The Gap). Canberra (AUST): COAG, 2012 